\title{
Inadvertent insertion of a Foley's catheter through the orifice of a duplex ureter during catheterisation for laparotomy
}

\author{
E. Papacharalabous $\cdot$ M. Ford $\cdot$ S. Butler-Manuel . \\ A. Tailor
}

Received: 20 January 2009 / Accepted: 25 February 2009/Published online: 10 March 2009

(C) Springer-Verlag 2009

\begin{abstract}
We report a case of inadvertent insertion of a 14-Fr Foley's catheter through the orifice of one branch of a previously unrecognised duplex ureter. The unintentional insertion of the catheter occurred at urethral catheterisation during laparotomy for gynaecological malignancy and lead to false intraoperative identification of the female anatomy and injury to the ureter. Postoperatively, cystoscopy and intravenous urography confirmed the existence of a duplex ureter on the affected side.
\end{abstract}

Keywords Duplex ureter · Catheterisation · Ureteric injury · Ureteral injury · Inadvertent

\section{Case report}

A 68-year-old woman underwent secondary debulking surgery for recurrent peritoneal malignancy under the care of the gynaecological oncology team in our tertiary centre for gynaecological cancer. During the laparotomy, in addition to small intraperitoneal secondary deposits, a $4 \mathrm{~cm} \times 3 \mathrm{~cm} \times 3 \mathrm{~cm}$ smooth and firm oval-shaped pelvic mass was recognised lateral to the left ureter (Fig. 1). Dissection revealed that the mass was no other than the balloon of the 14-Fr Foley's urethral catheter that had been unintentionally inserted through the ureteric orifice

E. Papacharalabous $(\bowtie) \cdot$ M. Ford $\cdot S$. Butler-Manuel $\cdot$ A. Tailor Department of Gynaecological Oncology,

Royal Surrey County Hospital,

Guildford, UK

e-mail: epapacharalabous@doctors.org.uk in one branch of a previously unrecognised duplex left ureter.

Following recognition, it became apparent that the ureter had suffered injury by both the inflation of the catheter balloon and by the surgical dissection and was torn obliquely. The catheter was subsequently withdrawn, the ureter was repaired surgically, and a ureteric stent was inserted for 4 weeks. Postoperative recovery was uneventful.

At immediate postoperative investigation, cystoscopy revealed the presence of three ureteric orifices (Fig. 2). Intravenous urography performed 6 weeks postoperatively confirmed the diagnosis of a left duplex ureter and the absence of any obstruction (Fig. 3).

\section{Discussion}

Duplication of the ureter and the renal pelvis is a common anomaly with an incidence of approximately $0.8 \%$, with unilateral duplication six times more frequent than bilateral [1].

Inadvertent ureteric catheterisation has been reported in the past in conjunction with microtip catheters during cystometry [2-4], during routine catheterization with a Foley's catheter in a case of a paraplegic patient [5], and in the case of long-term catheterisation of a fibrotic bladder [6]. Alternatively, similar cases have been reported during retropubic suspension [7] and as the result of suprapubic catheter insertion [8]. Such a complication may be associated with postoperative anatomical changes. [6].

Urethral catheterisation for urinary bladder drainage is a routine procedure at laparotomy. Accidental insertion of the 


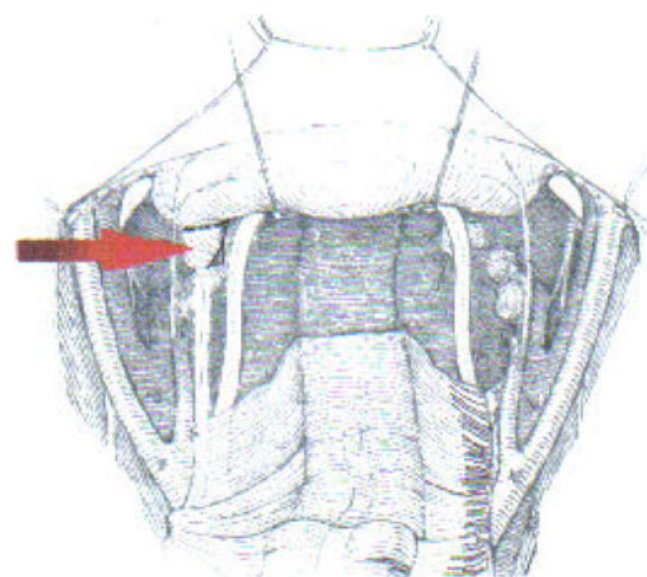

Fig. 1 A smooth and firm oval-shaped pelvic mass was recognised lateral to the left ureter

tip of the Foley's catheter into the ureteric orifice may be avoided by gently tugging on the catheter after inflating the catheter tip [4].

To our knowledge, this is the first reported case of inadvertent catheterisation of a ureter during laparotomy in gynaecology, and it clearly points out an extremely rare but potentially hazardous complication. It has been advocated that accidental ureteral catheterisation may be associated with similar complications to those arising from ureteral stents or ureteroscopy, which include ureteral disruption, permanent dilatation, stricture, and upper tract infection [2].

Ureteric injury during abdominal and pelvic surgery has an incidence of $0.2-1 \%$, with half of the injuries occurring during obstetric and gynaecological surgery [9].

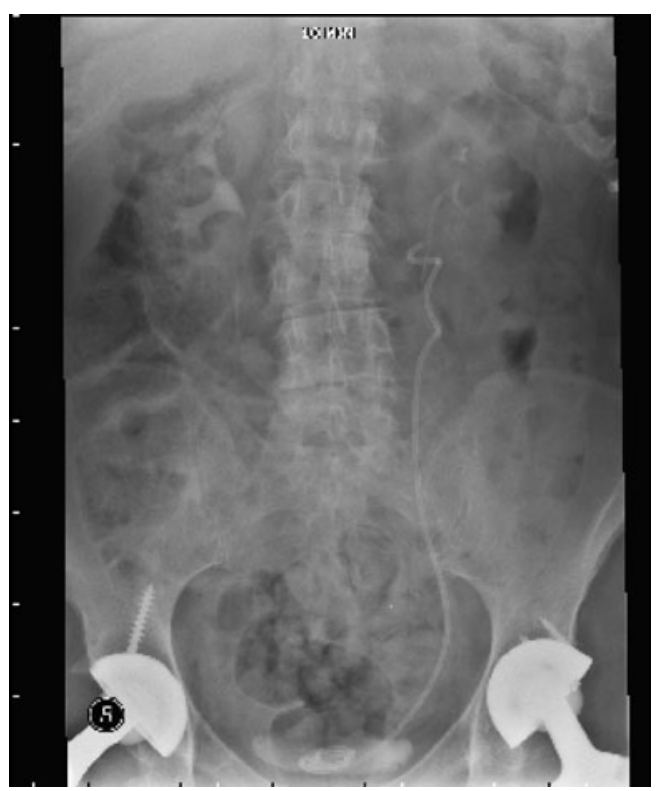

Fig. 3 A left duplex ureter and the absence of any obstruction

Intraoperative recognition and repair of ureteric injuries may be associated with decreased morbidity and lower litigation risk [10].

In our case, the unintentional catheterisation of the ureter was an unexpected finding as the position of one ureter on each side of the pelvis was only identified intraoperatively, and the existence of a duplex ureter was not suspected despite the previous history of primary debulking surgery and the appropriate preoperative imaging of the abdomen with MRI scan. No reported cases of inadvertent catheterisation of a Duplex ureter exist so far.
Fig. 2 Presence of three ureteric orifices revealed by cystoscopy

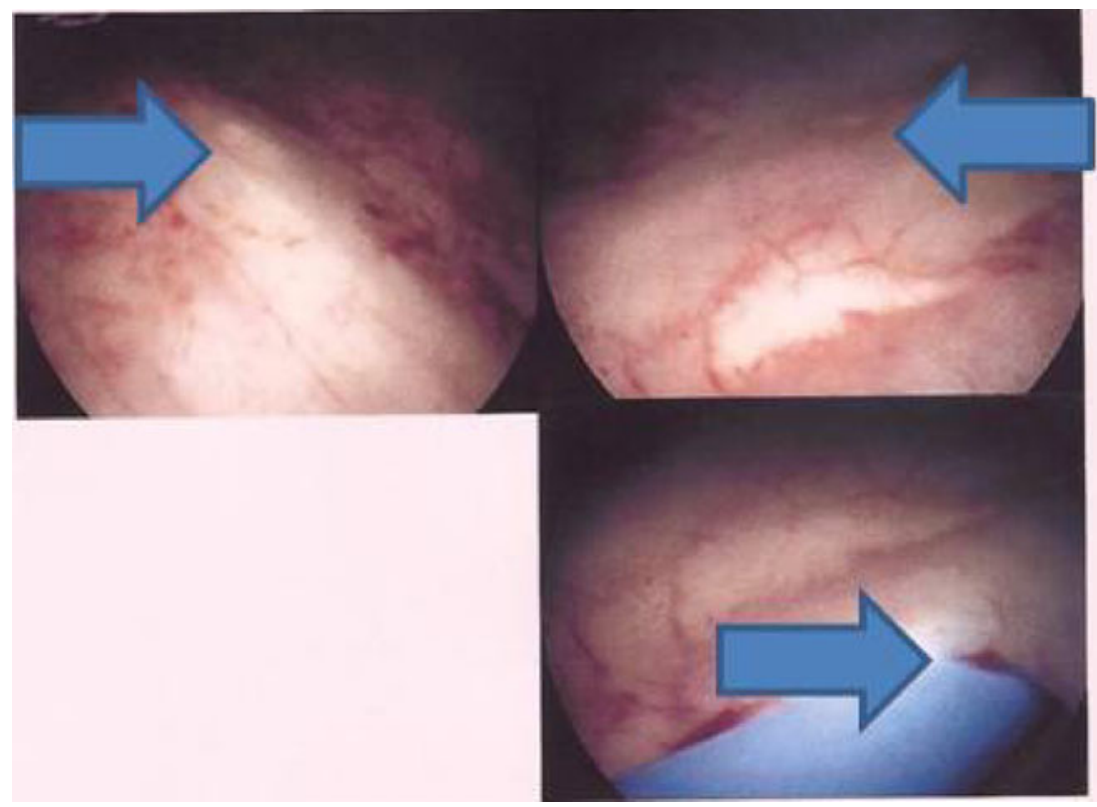




\section{References}

1. Snyder HMC (1987) The duplex system, ectopic ureter and ureterocele. In: Holliday MA, Barratt TM, Vernier RL (eds) Pediatric Nephrology, 2nd edn. Williams and Wilkins, Baltimore, pp 681-690

2. Ordonez E, Zivkovic F, Moser F, Tamussino K (1998) Inadvertent ureteral catheterizaion with a microtip catheter at cystometry. Int Urogynecol J Pelvic Floor Dysfunct 9(3):184-185

3. Gill EJ, Nichols CM (2002) Cystoscopic confirmation of inadvertent ureteral catheterization during cystometry. Int Urogyn J Pelvic Floor Dysfunct 13(4):266-267

4. Rao AR, Hanchanale VS, Motiwala HG, Karim O (2006) An unusual cause of acute loin pain during cystometry. Indian $\mathbf{J}$ Urology 22(3):268-269
5. George J, Tharion G (2005) Transient hydroureteronephrosis caused by a Foley's catheter tip in the right ureter. Scientific World Journal 2(5):367-369

6. Muneer A, Minhas S, Harrison SCW (2002) Aberrant Foley catheter placement into the proximal right ureter. BJU International 89(7):795

7. Hara N, Koike H, Bilim V, Takahashi K (2005) Placement of a urethral catheter into the ureter: an unexpected complication after retropubic suspension. Int J Urology 12(2):217-219

8. Borrero GO, Miller PR, Vora K, Nepjuk CA (1987) Acute ureteral obstruction as a complication of suprapubic catheterization. Urol Radiol 9(3):171-173

9. Purandare CN (2007) Urological injuries in gynaecology. J Obstet Gynaecol India 57(3):203-204

10. Gill EJ, Elser DM, Bonidie MJ et al (2001) The routine use of cystoscopy with the Burch procedure. Am J Obstet Gynecol 185 (2):345-348 